\title{
The hidden medical school: A longitudinal study of how social networks form, and how they relate to academic performance
}

Katherine Woolf ${ }^{1}$, Henry W W Potts ${ }^{2}$, Shalini Patel ${ }^{3}$, IC McManus ${ }^{1}$

\footnotetext{
${ }^{1}$ Academic Centre for Medical Education, UCL Medical School, Archway Campus, Highgate Hill, London N19 5LW

${ }^{2}$ Centre for Health Informatics and Multi-professional Education, UCL Division of Population Health, Archway Campus, Highgate Hill, London N19 5LW

${ }^{3}$ UCL Medical School, Gower Street London WC1E 6BT
}

Correspondence: Katherine Woolf k.woolf@ucl.ac.uk Academic Centre for Medical Education, UCL Medical School, Archway Campus, Highgate Hill, London N19 5LW 


\section{Abstract}

Background: UK medical schools typically have over 300 students per year, making it impossible for students to know all the others well.

Aims: This longitudinal cohort study measured the formation of medical student social networks and their relationship to grades.

Method: In November 2009, 215/317 (68\%) Year 2 UCL medical students reported their friendships with others in their year, by questionnaire. Multiple regression assessed the relationship between friendships, exam results and background variables (obtained from student records), with permutation testing to assess statistical significance.

Results: Students of the same sex, the same ethnic group, and in the same tutor and small groups (to which they were randomly assigned at the start of medical school) were socially closer. Taking into account absolute difference in Year 1 grades, Year 2 pairs who were socially closer in November 2009 had more similar May 2010 grades. Individual student variables did not predict similarity in 2010 grades after taking friendships into account.

Conclusions: The results suggest that medical students chose friends of the same sex and ethnic group as themselves; but random allocation of students to tutor groups also influenced friendships. Most importantly, friendships related to subsequent exam performance, suggesting friendship may influence learning. 


\section{Introduction}

Medical schools in the UK have in recent years expanded rapidly, and now have three to four hundred students per year, compared with around 100-200 in the 1970s, and 30-50 in the 1950s (Lord Flowers, 1980). In such large year groups it is almost impossible for each student to know all of the others (Dunbar, 1993; Hill \& Dunbar, 2003). There are anecdotes of students only meeting each other for the first time when seated next to each other at the degree ceremony. Medical schools are traditionally tight-knit social structures, partly for historical and social reasons (Sinclair, 1997) and partly because it is believed that friendships facilitate learning and improve team-working. But how do students choose with which other students to be friends, and do those friendships affect learning?

The formation and influence of social networks is the subject of much recent research. A standard finding is that friends typically are similar to one another, particularly on demographic factors (see McPherson, Smith-Lovin \& Cook, 2001 for a review). The causes of this homogeneity are potentially complex. People may choose to associate with those similar to themselves, a preference that Wimmer \& Lewis (2010) call homophily, literally 'love of the same' (although some researchers use homophily to describe the observed homogeneity in friendship groups rather than to describe the underlying causal mechanism of preference) (McPherson et al. 2001). Similarity of attitudes or behaviours may also result from peer influence, either mutual or unilateral. 
The belief that friends and peers influence each others' behaviour and attitudes is longstanding, widespread, and seems intuitively to make sense (Marmaros \& Sacerdote, 2006). Social networks are crucial for the sharing of information and the spread of learned behaviours (Coleman, Katz \& Menzel, 1957; Jackson, 2008; Jippes, Achterkamp, Brand, Kiewiet, Pols \& van Engelen, 2010). However the ability to distinguish between peer influence and homophily becomes important when trying to measure accurately how much similarity on specific outcomes such as smoking behaviour (Mercken, Snijders, Steglick, Vartiainen \& de Vries, 2010), obesity (Christakis \& Fowler, 2007), happiness (Fowler \& Christakis, 2008), loneliness (Cacioppo, Fowler, Christakis, 2009) or academic grades is due to the influence of peers. To make matters more complicated, homophily and peer influence are not the only possible causes of homogeneity in attitudes or behaviours, and influence cannot be the origin of homogeneity for fixed factors such as ethnicity or sex. Confounding can also occur when people are affected in the same way by other environmental factors, for example students in the same class receiving the same teaching, or coming from similar socioeconomic backgrounds due to the neighbourhood the school is in (Fowler \& Christakis, 2008; Manski, 1993).

Researchers have used various methods to try to disentangle peer effects from homophily and other causes of observed homogeneity. Some have collected longitudinal data and inferred causality from changes over time (Christakis \& Fowler, 2007; Fowler \& Christakis, 2008; Arcidiacono \& Nicholson, 2005). Others have taken advantages of quasi-experimental situations in which strangers are randomly allocated to social environments such as college dormitories or classrooms (Sacerdote, 2011; Zimmerman, 2003; Kang, 2007; Foster, 2006). The evidence for peer influence on outcomes from 
such studies is mixed. Many find evidence for peer effects on individuals' health (Christakis \& Fowler, 2007; Fowler \& Christakis, 2008) and academic outcomes (Sacerdote, 2001; Zimmerman, 2003; Kang, 2007); others, including the only study we found on medical students (Arcidiacono \& Nicholson, 2005) find small or non-significant effects once environmental and other factors have been accounted for (Foster, 2006; Cohen-Cole \& Fletcher, 2008).

In this study we used a combination of longitudinal and quasi-experimental methods to map the social network in one cohort of Year 2 UCL medical students, to examine how demography and propinquity (geographic closeness) influence the formation of friendship, and to assess the influence of friendships on the examination performance of students. Specifically, we sought to explore whether:

1. Belonging to a particular ethnic and/or gender group influenced friendship formation;

2. Random allocation to a Professional Development Spine (PDS) tutor group, small group or campus influenced friendship formation;

3. The closeness of friendships related to individuals' subsequent examination grades, taking into account previous examination grades.

\section{Method}

\section{Participants}

Eligible participants were all UCL medical students entering Year 2 in 2009/2010 for the first time $(\mathrm{n}=318)$. Six repeating students were excluded. 


\section{Data collection}

We collected social network data using a questionnaire. Demographic, propinquity and examination data were extracted from student records.

\section{Social network data}

In October 2009, we emailed all Year 2 UCL Medical School students an invitation to participate in the study. We explained that it would consist of a short questionnaire that would be given out in a lecture two weeks hence, and would also require students to allow us to access demographic and exam data from their student records. We asked anyone who did not wish to take part to respond.

Two weeks later we distributed the questionnaire to all students attending two consecutive Year 2 lectures. At the start of each lecture, SP gave a three-minute briefing explaining the purpose of the study, how to complete the questionnaire, and about the incentive, which was the chance to win one of ten $£ 10$ prizes or one $£ 50$ prize based on a random selection from the completed questionnaires. The questionnaire contained a covering information/consent form stapled to a list of all the students in Year 2, excluding anyone who had opted out via email. To help ensure confidentiality, participants completed the information/consent form using their university ID number and initials. The information/consent form and the student list were numbered with a unique identifier and separated before analysis.

After reading and completing the information/consent form, participants completed the questionnaire by underlining those in the year with whom they were friends (see Figure 
1). Giving students a roster and asking them to indicate their friends is a well-recognised method of generating social network data ( $c f$ Harris, Halpern, Whitsel et al., 2009). We designed the wording to try to ensure that students gave us the names of people they actually interacted with and might have an influence on them.

Figure 1 about here

\section{Demographic variables}

We obtained information on sex and self-reported ethnicity (using 2001 UK census categories) from student records. As some of the categories contained very few people, we grouped ethnicity both into six categories (white, Indian, Pakistani/Bangladeshi, Black, Chinese and 'all other', called Ethnic6), and also into two categories (white, nonwhite, called Ethnic2).

\section{Propinquity variables}

We used Year 1 PDS group, small group, and campus as measures of propinquity.

\section{Examination variables}

Students sat written, machine-marked, multiple choice assessments in May, just before the end of each academic year. Year 1 final summative assessment grades were measured retrospectively, and Year 2 final summative assessment grades were measured prospectively. Year 1 and Year 2 grades were summarised as the mean of four written assessments, calculated by UCL medical student administration. Where students had failed Year 1 and taken resits or retaken the whole year (and thus ended up with two sets 
of Year 1 grades), we used only the first, failing, grade. To compare Year 1 and Year 2 scores, we $z$-transformed all grades (mean of zero, standard deviation of one).

\section{Statistical and Network Analyses}

We gave each participant a unique number pertaining to their position on the questionnaire list of students. This was called their "order number" and was used to identify them for all of the analyses.

We imported the data into Pajek (http://pajek.imfm.si/doku.php?id=pajek) and C-finder (http://www.cfinder.org/) software to visualise the network and to calculate network statistics, and into Matlab to perform multiple regressions using permutation testing. Further details of the analyses are given in the Appendix. We analysed the network on the basis that all ties were of equivalent strength, were reciprocal and were undirected (if individual A said they were friends with B, but B did not say they were friends with A, a friendship between A and B was taken to exist).

\section{Visualisation of the network}

We used Pajek to partition the entire network according to continuous variables (e.g. grades) and categorical variables (e.g. ethnicity), thus creating 'sub-networks', which we examined visually for structural homogeneity.

In social network analysis, people are represented as 'nodes' and social ties are represented by lines ('edges'). We used C-finder software to visualise the densest parts of the network in terms of its cliques and communities, which we then eyeballed for homogeneity in terms of demographic, propinquity and examination variables. In C- 
finder, a $k$-clique is a saturated (i.e. entirely interconnected) group of $k$ nodes. A $k$ community is a group of $k$-cliques connected by $(k-1)$ nodes. The cliques and communities are organised hierarchically, so cliques or communities larger than $k=3$ must contain smaller cliques. For example, a 4-clique (clique of four nodes) will contain four 3-cliques. See Figure 2. However, not all smaller cliques will necessarily be subsumed into larger cliques because a 3-clique can exist independently of the rest of the network.

Figure 2 about here

\section{Multiple regression analyses}

A network can be considered in terms of the relationship between all possible pairs of individuals (dyads), with a friendship between two particularly people (nodes) being represented as an edge (tie) between the two nodes. If two people are not friends, but both are friends with a third person, they are connected indirectly, Indirect connections may also go through multiple intermediaries. We calculated the closeness of any dyad, with high values indicating a pair of individuals who are closer in the network using Dijkstra's algorithm (see http://en.wikipedia.org/wiki/Dijkstra\%27s_algorithm) with the function dijkstra_sp in the MatlabBGL library

(http://www.stanford.edu/ dgleich/programs/matlab_bgl/). The Dijkstra distance is larger when individuals are further apart. We therefore describe the social network of medical students in the November of Year 2 in terms of the negative Dijkstra distance, which we refer to as 'closeness'. Closeness scores varied from 0 (the closeness of a person to his or herself), through to -1 (a pair with a direct tie in the network) through to -5 (the furthest apart that we found in our network). 
We made an analysis plan before collecting the data to perform one multiple regression to assess the influence of background variables (gender, ethnicity, PDS group, small group, campus, Year 1 exam scores) on network closeness (i.e. friendship) and another to assess the influence of network closeness on Year 2 exam scores across all possible dyads, taking into account background variables. Statistical significance was assessed by comparing the $b$ estimates from those regression analyses with the $b^{*}$ estimates calculated using 10,000 random permutations of the dependent variable matrix using the quadratic assignment procedure (see Hubert, 1985; Krackardt, 1987; Krackardt, 1988). All hypotheses were one-tailed (since it was always hypothesised that being closer in the social network would be related to greater similarity in demographic, propinquity or examination variables), and are reported using $p$-values, calculated as the number of permutations out of 10,000 in which the coefficients from randomised networks $\left(b^{*}\right)$ were larger than the actual coefficients $(b)$.

\section{Results}

\section{Participants and response rate}

One student opted out prior to the questionnaire being administered and was therefore excluded. Of the remaining 317 eligible participants 215 (68\%) completed a questionnaire and thus provided social network data for all participants. 143 of the 317 participants $(45 \%)$ were female. Twelve were missing ethnicity, and of the remaining $305,159(52 \%)$ were of white ethnicity. See Table 1. 
Table 1 about here

\section{Network statistics}

There were 3,057 edges in the network. The largest number of nodes connected to a single other node was 60 , and the smallest was 1 , with the distribution positively skewed. The median number of connections per node was 17 , and the mean was 19 . The average distance between two random nodes in the network was 2.3, and the longest distance between two nodes was 5 .

\section{Visualisation of the network}

The size of the network meant it was extremely complex when visualised; however when the nodes were coloured by Ethnic2 (Figure 3a) and Ethnic6 (Figure 3b) in Pajek, clustering was clearly visible. Clustering on the basis of other variables was less visually obvious.

Figures $3 \mathrm{a}$ and $3 \mathrm{~b}$ about here

C-finder found the largest community (i.e. the largest tight-knit group) in the network. It consisted of two overlapping 13-cliques with a total of 14 students. The community contained nine males and five females, all of whom were non-white. Ten students were Indian and four were in the category 'all other'. Using more detailed census categories revealed the 'all other' students to be self-categorised as 'Asian Other' (i.e. Asian, but not Indian, Pakistani, Bangladeshi or Chinese). Given $48 \%$ (146/305) of the students with ethnicity data were from non-white groups, the probability of selecting 14 non-white students by chance is very low $(\mathrm{p}<0.0001)$. After expanding the visualisation to include 
communities that contained smaller cliques and therefore more students, clustering by ethnicity was still obvious. For example, there were five communities containing cliques of size $k=10$ (totalling 45 students). Two communities were exclusively white and one consisted of all white students except for one student of mixed (white and Asian) ethnicity. The other two communities were entirely non-white. See Figure 4.

Figure 4 about here

An alternative way of seeing the entire network is shown in Figure 5. Individuals, in the same order on the rows and columns, are sorted by ethnicity, but are otherwise random within ethnicities. Different colours show the various ethnic groupings, green being 'white ethnicity', other colours being 'non-white ethnicity'. Dots indicate direct ties (friendships) between pairs of individuals, and therefore dots within each coloured square represent the friendships between members of that ethnic group. Friendships between, but not within, the four Indian subcontinent groups (Indian, Pakistani, Bangladeshi and Asian Other) are shown in the pale blue area. Friendships between the Indian Subcontinent groups and the other non-white groups are shown in the pale pink area. The clustering within ethnic groups in Figure 5a is more apparent visually if one compares it with Figure 5b in which the network remains the same but ethnicities have been assigned at randomised. The relative lack of white/non-white friendships in the actual network can be seen in the sparseness of the upper right and lower left hand quadrants of Figure $5 \mathrm{a}$ when compared to Figure $5 b$.

Figures $5 \mathrm{a}$ and $5 \mathrm{~b}$ about here 


\section{Statistical analysis}

The statistical analyses asked two separate types of question:

- what factors, such as sex, ethnicity and propinquity, predict the presence of links between individuals within the social network?; and

- how do links within the social network predict the similarity of individuals in terms of characteristics such as examination performance?

Both can be assessed in terms of a multiple regression, and the analyses can be conceptualised and visualised in terms of a path model (Figure 6).

Figure 6 about here

\section{Predictors of the Social Network}

In the first analysis, we regressed Dijkstra distance in Year 2 (i.e. closeness in the social network) on sex, the two ethnicity measures, PDS group, small group, campus, and Year 1 exam grades. All significance levels were calculated after taking other effects into account. Dyads of the same sex were closer (beta $=0.030, p=0.0001)$. There was a strong effect of Ethnic2 (white/non-white; beta $=0.117, \mathrm{p}<0.0001$ ), dyads of the same ethnic grouping being closer, but there was no additional effect of Ethnic6 (beta $=0.041$, $\mathrm{p}=0.111)$. Dyads were also closer if students were in the same PDS group $($ beta $=0.128$, $\mathrm{p}<0.0001$ ) and small group (beta $=0.020, \mathrm{p}=0.0005$ ), but the effect of campus was not significant (beta $=0.007, \mathrm{p}=0.180$ ). There was no influence of Year 1 exam results on closeness (beta $=0.055, \mathrm{p}=0.381$ ). Thus, students in Year 2 were closer in the social network if they were of the same sex, of the same ethnicity (white/non-white distinction), 
and in the same PDS and small group, but there was no relationship with the finer level ethnicity categorisation, campus or Year 1 exam result.

\section{Predictors of Year 2 performance}

We next sought to test the influence of the social network upon performance in the absolute difference in Year 2 exam performance for all possible dyads, after absolute difference in Year 1 performance was taken into account (see figure 6), the latter being highly significant (beta $=0.517, \mathrm{p}<0.0001)$. Dyads which were more similar in their Year 2 performance, after taking Year 1 performance into account, were closer together in the social network, i.e. a smaller absolute Dijkstra distance (beta $=0.043, \mathrm{p}=0.0143$ ). This significance level is based on 10,000 random permutations. In view of the theoretical importance of this significance level, the analysis was repeated with 100,000 randomisations, which gave $\mathrm{p}=0.0129$. Thus, students who were closer in the social network had more similar Year 2 exam score, i.e. being close to other students with above average exam performance was associated with improved performance by an individual, and being close to other students with below average exam performance was associated with worse performance by an individual.

In a separate multiple regression, Year 2 performance was also assessed in relation to Year 1 teaching groups, campus, sex and ethnicity, with no effects being significant after taking closeness in the network into account, suggesting that the effects are mediated via closeness (which itself is related to teaching groups, sex and ethnicity). 


\section{Discussion}

This study, which to our knowledge is the first to measure social networks in medical students, has shown that exam results in medical school are not only influenced by characteristics of individual medical students, but also by what we call 'the hidden medical school', the network of social relationships between medical students. Our results suggest that the people that a student knows at the start of Year 2 influences how well they perform in their examinations over six months later.

The process by which the social network forms in the medical school is not clear, although it is important to remember that almost no students would have known one another prior to arriving at medical school. As in all social networks, serendipity, homophily and propinquity probably all play their parts. It is not surprising, but it is important, that there is clustering by sex and ethnicity, which has been noted in studies of non-medical students (Wimmer \& Lewis, 2010; Marmaros \& Sacerdote, 2006; Mayer \& Puller, 2008; Fischer, 2008; Goodreau, Kitts \& Morris, 2009). More interesting is that the social network has also been influenced by the medical school that, by randomly allocating students to teaching groups, has created friendships. A key finding of this study is that closeness in the social network predicts similarity in academic achievement at the end of Year 2, even taking into account Year 1 achievement. That means that students doing well were more closely linked socially to other students who were also doing well, and that students who were performing poorly were more closely linked socially to other students who were also performing poorly. 
The use of multiple regression analyses with longitudinal data enabled us to look at the independent effects of background variables on outcomes, in effect importing the logic of structural equation modelling into the analysis of social networks. This study also has certain weaknesses. The questionnaire had a response rate of $68 \%$ meaning nonrespondents were those who did not attend the lectures during which it was administered and therefore may have been less conscientious. It also means potentially important friendships between non-respondents were left unreported. We assumed all reported friendships were reciprocal. This assumption is often made (e.g. Mayer \& Puller, 2008). It gave us data on the rest of the students in the year because students could report friendships with non-respondents; however, it also prevented us from analysing the hierarchies within the social network, which would have shown us the amount of social influence individuals exerted on each other. We were explicit about the types of friendships we wanted students to report, which could have led to under-reporting of other potentially important friendships. We only captured the social network at one time point. Had we measured the social network in Year 1 we would have been able to see how it changed in Year 2, and how this related to changes between Year 1 and Year 2 grades, which would have given us a stronger indication of the causality of the link between friendships, learning and grades. We chose to consider all reported links, weak or strong, partly because the weighting had little influence upon the outcome of the analyses, and partly because there is a standard finding in social network research which suggests that weak links are particularly important in allowing connections between groups which otherwise are not connected (Granovetter, 1973). 
Our finding that network closeness predicted similarity in academic performance suggests that student learning did not arise solely from lectures and tutorials. Informal learning, where a pair of students collaborate in their studying, discussing ideas, testing each other, enquiring of each other, and explaining to each other, may result in both doing better. Friends may give each other practical resources, such as past exam papers. Alternatively, weak students who are close together in a network may reinforce in one another a dislike for work, a disinclination to study, and so on. Friendships may also alter a student's internalised norms relating to learning or exam performance, so, for example, a student's perception of how many hours' study constitutes 'hard work' may change in light of their friends' opinions ( $c f$. Fowler \& Christakis, 2008).

Studies of social networks also generally find, as we did, clustering by ethnicity. McPherson et al. (2001) point out that:

"race and ethnicity are clearly the biggest divide in social networks in the United States today" (p 420)

Those authors go on to explain that these divisions are partly explained by structural inequalities in, for example, education and health, by differences in the size of various ethnic groups, and by prejudice. One might expect, therefore, that ethnic homogeneity would be less evident in a UK medical school, where structural inequalities are fewer, and - one might hope - prejudice is less prominent. However our findings suggest that, even at this London medical school, ethnicity is an important factor in friendship 
formation. Homophily is a likely cause. At the start of the year, when most people know no-one, students will look for similar others with whom to form friendships. A student may use ethnicity as a surrogate for beliefs and attitudes, presuming - possibly erroneously - that because someone is a member of their own ethnic group, they hold similar values to themselves, and also presuming that people from a different ethnic group hold different values (Ames, 2004; Goel, Mason, \& Watts, 2010). The other side of the coin from homophily is neophobia, fear of the unknown, and there is plenty of evidence that people are anxious about and will avoid social encounters with people from unfamiliar ethnic groups (Turner, Hewstone \& Voci, 2007). In addition, ethnicity may have been confounded with other factors that might influence friendship formation, such as belonging to a particular club or society, as illustrated by this quote from a British Medical Association (2004) report on the demography of medical schools:

"I must admit that in medical school there is sometimes an invisible divide between groups of students based on their ethnicity, these groups fuelled by societies exclusively for people of a certain ethnicity.” (p 46)

Does it matter if students preferentially form friendships with others from the same ethnic group? One might argue that it could benefit students from minority groups to stick together as they can provide each other with moral support and so on. However, academic achievement in medical school is known to be influenced by the ethnicity and the sex of students (Ferguson, James \& Madeley, 2002; Woolf, Potts, McManus, 2011). Since most medical students enter medical school with high and broadly equivalent 
academic achievement, the appearance of differences dependent upon sex and ethnicity is not straightforward to explain (and most individual difference variables studied, e.g. learning habits, have little impact on differences in achievement, and in particular do not account for ethnic differences in attainment: Woolf, McManus, Potts, Dacre, in press, British Journal of Educational Psychology). Social networks potentially provide an explanation for ethnic differences in attainment, since networks are heavily structured by ethnicity, and the network itself influences achievement. Importantly, the influence of randomisation into teaching groups upon network formation suggests that networks can be broadened and diversified explicitly. Unlike lectures, where numbers are huge and seating is often clustered by ethnicity ( $c f$ Clack, Dixon \& Tredoux, 2005), tutorial groups encourage continuing, high quality contact between students of different ethnicities, allowing trust to form, anxiety at intergroup contact to be reduced, and stereotypes to be challenged. This type of environment may improve students' tolerance of cultural differences (Pettigrew, 1998; Pettigrew \& Tropp, 2006; Pettigrew \& Tropp, 2008;) and may even help reduce the disparity in the achievement of different ethnic groups.

\section{Conclusion}

This preliminary study of the social network in one cohort of medical students at a single university suggests sex and particularly ethnicity lead students to divide themselves into 'hidden medical schools', and that resultant friendships can impact on exam results. While constructivist models of learning as a social activity are widely accepted, quantitative analyses of how social relationships affect learning are rare. The field of social networks research is fast moving, and new techniques that exploit evermore powerful computers are being developed to study the formation of social networks and their influence on individuals over time (Snijders, van de Bunt \& Steglich, 2010). By the 
simple act of randomisation into teaching groups, medical schools can, in effect, encourage diversification of students' friendship groups, and by understanding how social networks operate at medical school and beyond, we can begin to truly understand and influence the previously hidden aspects of medical education. 


\section{Practice Points}

- The friendships made at medical school are often thought to influence learning, but there is no previous quantitative evidence for this assumption.

- Year 2 UCL medical students were more likely to chose friends of the same sex and ethnic group as themselves; however, the Medical School's random allocation of students to tutor groups also influenced their choice of friends

- Students' choice of friends had a significant influence on their examination grades, even after taking their previous grades into account

- The results provide insight into previously hidden aspects of medical education that medical schools may wish to influence

- Further research is required to explore whether medical students' friendships influence other aspects of their behaviour or outcomes

\section{Notes on contributors}

Katherine Woolf is a Lecturer in Medical Education at the Academic Centre for Medical Education in UCL Medical School, UK.

Henry W W Potts is a Senior Lecturer in Health Informatics at the Centre for Health Informatics and Multi-professional Education in the UCL Division of Population Health, UK.

Shalini Patel is a medical student at UCL Medical School, UK. 
IC McManus is a Professor of Psychology and Medical Education in the Academic Centre for Medical Education in UCL Medical School, UK.

\section{Declaration of Interest}

The authors report no declarations of interest.

\section{Details of contributors}

Katherine Woolf and IC McManus conceived of the idea and designed the study. All authors contributed to the analysis and interpretation of the data. Katherine Woolf, IC McManus and Henry Potts drafted the article and revised it critically. All authors approved the final version to be published.

\section{Ethical approval}

The study was approved by the UCL Research Ethics Committee (0511/002).

\section{References}

Ames DR. Strategies for Social Inference: A Similarity Contingency Model of Projection and Stereotyping in Attribute Prevalence Estimates. Journal of Personality and Social Psychology 2004; 87(5):573-585.

Arcidiacono P, Nicholson S. Peer effects in medical school. Journal of Public Economics 2005; 89(2-3):327-350. 
British Medical Association. Demography of medical schools - a discussion paper. 2004. London, British Medical Association.

Christakis NA, Fowler JH. The Spread of Obesity in a Large Social Network over 32 Years. New England Journal of Medicine 2007; 357(4):370-379.

Clack B, Dixon J, Tredoux C. Eating together apart: patterns of segregation in a multiethnic cafeteria. Journal of Community Applied Social Psychology 2005; 15(1):116.

Cohen-Cole E, Fletcher JM. Is obesity contagious? Social networks vs. environmental factors in the obesity epidemic. Journal of Health Economics 2008; 27(5):13821387.

Coleman J, Katz E, Menzel H. The Diffusion of an Innovation Among Physicians. Sociometry 1957; 20(4):253-270.

Dunbar RIM. Coevolution of neocortical size, group size and language in humans. Behavioral and Brain Sciences 1993; 16:681-694.

Ferguson E, James D, Madeley L. Factors associated with success in medical school: systematic review of the literature. BMJ 2002; 324(7343):952-957.

Fischer MJ. Does Campus Diversity Promote Friendship Diversity? A Look at Interracial Friendships in College*. Social Science Quarterly 2008; 89(3):631-655.

Foster G. It's not your peers, and it's not your friends: Some progress toward understanding the educational peer effect mechanism. Journal of Public Economics 2006; 90(8-9):1455-1475. 
Fowler JH, Christakis NA. Dynamic spread of happiness in a large social network: longitudinal analysis over 20 years in the Framingham Heart Study. BMJ 2008; 337.

Goel S, Mason W, Watts DJ. Real and Perceived Attitude Agreement in Social Networks. Journal of Personality and Social Psychology 2010; 99(4):611-621.

Goodreau SM, Kitts JA, Morris M. Birds of a Feather, or Friend of a Friend? Using Exponential Random Graph Models to Investigate Adolescent Social Networks. Demography 2009; 46(1):103-125.

Granovetter MS. The Strength of Weak Ties. American Journal of Sociology 1973; 78(6):1360-1380.

Harris, K.M., C.T. Halpern, E. Whitsel, J. Hussey, J. Tabor, P. Entzel, and J.R. Udry. 2009. The National Longitudinal Study of Adolescent Health: Research Design [WWW document]. URL: http://www.cpc.unc.edu/projects/addhealth/design.

Hill R, Dunbar R. Social network size in humans. Human Nature 2003; 14(1):53-72.

Hubert L. Combinatorial data analysis: Association and partial association. Psychometrika 1985; 50(4):449-467.

Jackson MO. Social and economic networks. Princeton: Princeton University Press; 2008.

Jippes E, Achterkamp MC, Brand PLP, Kiewiet DJ, Pols J, van Engelen JML. Disseminating educational innovations in health care practice: Training versus social networks. Social Science \& Medicine 2010; 70(10):1509-1517. 
Kang C. Classroom peer effects and academic achievement: Quasi-randomisation evidence from South Korea. Journal of Urban Economics 2007; 61(3):458-495.

Krackardt D. QAP partialling as a test of spuriousness. Social Networks 1987; 9(2):171186.

Krackhardt D. Predicting with networks: Nonparametric multiple regression analysis of dyadic data. Social Networks 1988; 10(4):359-381

Lord Flowers. London Medical Education: a New Framework. Report of a Working Party on Medical and Dental Teaching Resources. 1980. University of London.

Manski CF. Identification of Endogenous Social Effects: The Reflection Problem. The Review of Economic Studies 1993; 60(3):531-542.

Marmaros D, Sacerdote B. How do Friendships Form? Quarterly Journal of Economics 2006; 121(1):79-119.

Mayer A, Puller SL. The old boy (and girl) network: Social network formation on university campuses. Journal of Public Economics 2008; 92(1-2):329-347.

McPherson M, Smith-Lovin L, Cook JM. Birds of a feather: Homophily in Social Networks. Annual Review of Sociology 2001; 27(1):415-444.

Mercken L, Snijders TAB, Steglich C, Vartiainen E, de Vries H. Dynamics of adolescent friendship networks and smoking behavior. Social Networks 2010; 32(1):72-81.

Pettigrew TF, Tropp LR. A Meta-Analytic Test of Intergroup Contact Theory. Journal of Personality and Social Psychology 2006; 90(5):751-783. 
Pettigrew TF, Tropp LR. How does intergroup contact reduce prejudice? Meta-analytic tests of three mediators. European Journal of Social Psychology 2008; 38(6):922934.

Pettigrew TF. Intergroup Contact Theory. Annual Review of Psychology 1998; 49(1):6585.

Sacerdote B. Peer Effects with Random Assignment: Results for Dartmouth Roommates. Quarterly Journal of Economics 2001; 116(2):681-704.

Sinclair S. Making doctors: an institutional apprenticeship. Oxford: Berg; 1997.

Snijders TAB, van de Bunt GG, Steglich CEG. Introduction to stochastic actor-based models for network dynamics. Social Networks 2010; 32(1):44-60.

Turner RN, Hewstone M, Voci A. Reducing Explicit and Implicit Outgroup Prejudice Via Direct and Extended Contact: The Mediating Role of Self-Disclosure and Intergroup Anxiety. Journal of Personality and Social Psychology 2007; 93(3):369388.

Wimmer A, Lewis K. Beyond and Below Racial Homophily: ERG Models of a Friendship Network Documented on Facebook. The American Journal of Sociology 2010; 116(2):583-642.

Woolf K, Potts HWW, McManus IC. Ethnicity and academic performance in UK trained doctors and medical students: systematic review and meta-analysis. BMJ 2011; 342. 
Woolf K, McManus IC, Potts HWW, Dacre J. The mediators of minority ethnic

underperformance in final medical school examinations. In press. British Journal of

Educational Psychology

Zimmerman DJ. Peer Effects in Academic Outcomes: Evidence from a Natural

Experiment. Review of Economics and Statistics 2003; 85(1):9-23.

\section{List of figures}

Figure 1: Instructions to potential participants

Figure 2: Example of a 4-community (a) made up of two 4-cliques (b) and (c). Each 4clique also contains four 3 -cliques.

Figure 3. Visualisation of the network using the Fruchterman-Rheingold 2D algorithm in Pajek. a) nodes coloured by Ethnic2 (white=yellow; non-white=light blue) b) nodes coloured by Ethnic 6 (white=yellow; black=green; Indian=purple;

Pakistani/Bangladeshi=red; Chinese=dark blue; 'all other'=pink). Nodes with missing ethnic data coloured dark grey.

Figure 4: The five communities of 10-cliques identified in the network by $\mathrm{C}$-finder software. There were two distinct all-non-white communities ( $n=17$ and $n=13)$, and three communities (all $n=10$ ) containing white students and one mixed white and Asian student. The three white communities shared all but five students. They therefore overlap considerably and appear almost as one community in the diagram. Of the non-white communities, one was largely Indian with four 'Asian Other' nodes. The other contained five Pakistani, four 'Other', two 'Asian Other', one Indian and one black African node. The numbers on the nodes are the unique identifiers and the letters refer to sex ( $\mathrm{M}$ or $\mathrm{F}$ ) and ethnicity $(\mathrm{AsO}=\mathrm{Asian}$ Other; $\mathrm{BlA}=$ black African; Ind=Indian; Oth=Other; Pak=Pakistani; Whi=white).

Figure 5. The social network and ethnicity. Both figures are symmetrical along the diagonal. Dots represent links (friendships) between pairs. Dots within coloured squares show friendships within ethnic groups; dots in the light blue area show friendships between the four Indian subcontinent groups; and dots in the light pink area show friendships between Indian Subcontinent groups and other non-white groups. All are more prevalent in the actual ethnicity figure a) than in the random ethnicity figure b). Dots in the upper right and lower left quadrants show friendships between white and nonwhite groups. They are more prevalent in figure b). 
Figure 6. Path model showing the relationships between variables in the multiple regression analyses. Solid lines represent statistically significant relationships with their beta weights. Single headed arrows represent hypothesised causal paths. Double headed arrows represent simple correlations. Grey lines show tested but non-significant relationships. 
Table 1. Ethnicity of participants

\begin{tabular}{|r|r|r|}
\hline Ethnic group & Frequency & Percent \\
\hline White (British, Irish or Other) & 159 & 50.2 \\
\hline Asian or Asian British - Indian & 44 & 13.9 \\
\hline Asian or Asian British - Pakistani & 13 & 4.1 \\
\hline Asian or Asian British - Bangladeshi & 9 & 2.8 \\
\hline Asian or Asian British - Other & 18 & 5.7 \\
\hline Black or Black British - African & 12 & 3.8 \\
\hline Mixed - White and Black Caribbean or African & 2 & 0.6 \\
\hline Mixed - White and Asian & 9 & 2.8 \\
\hline Mixed - Other & 7 & 2.2 \\
\hline Chinese & 22 & 6.9 \\
\hline Other & 10 & 3.2 \\
\hline Missing & 12 & 3.8 \\
\hline Total & 317 & 100.0 \\
\hline
\end{tabular}


Here is a list of all the medical students in your year. Please:

Underline the names of students you know very well (e.g. phone about exciting events in your life, feel you could confide personal problems to, see very frequently etc). On average this will be no more than 2-3 people.

Circle the students you know quite well, and consider to be within your broad

circle of friends (e.g. chat with frequently, eat lunch with, often meet socially etc).

On average, this will be no more than 8-12 people.

Leave blank if you don't know a student, or feel no relationship beyond bumping in to them at medical school.

Figure 1: Instructions to potential participants 
a)

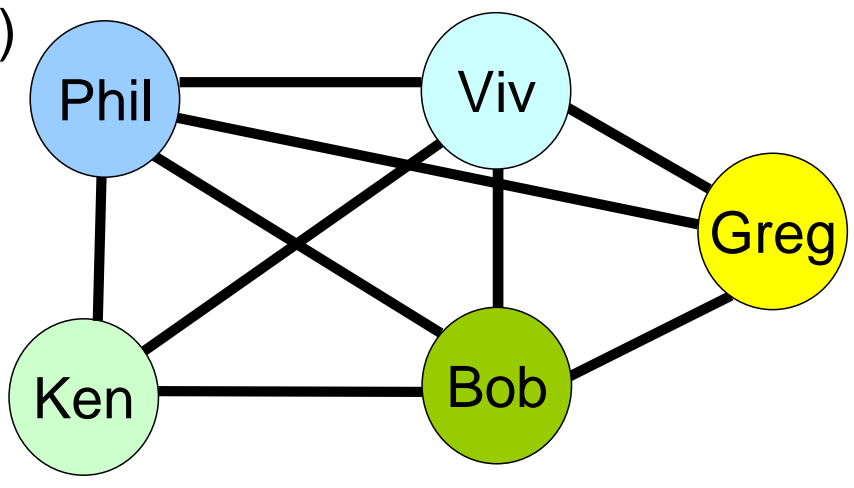

b)

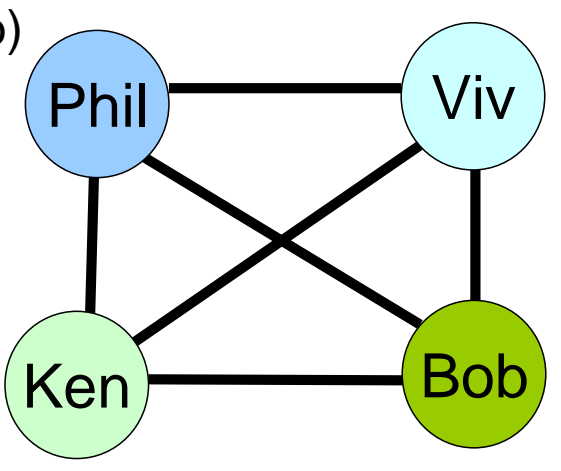

C)

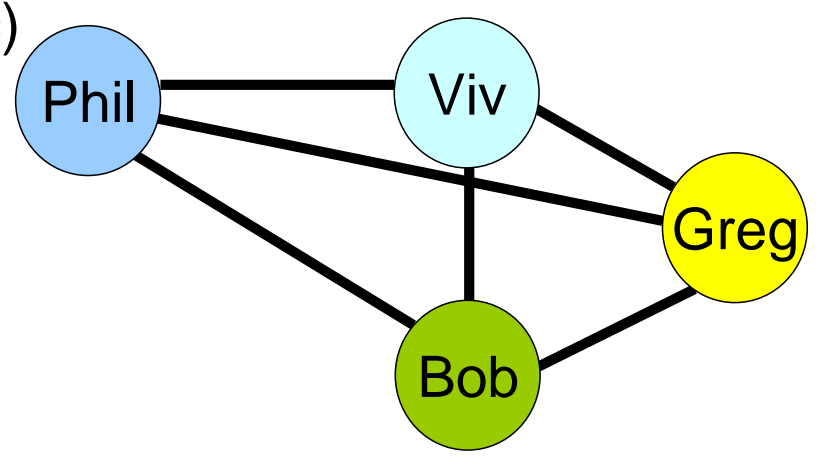

Figure 2: Example of a 4-community (a) made up of two 4-cliques (b) and (c). Each 4clique also contains four 3 -cliques. 
a) Ethnic2

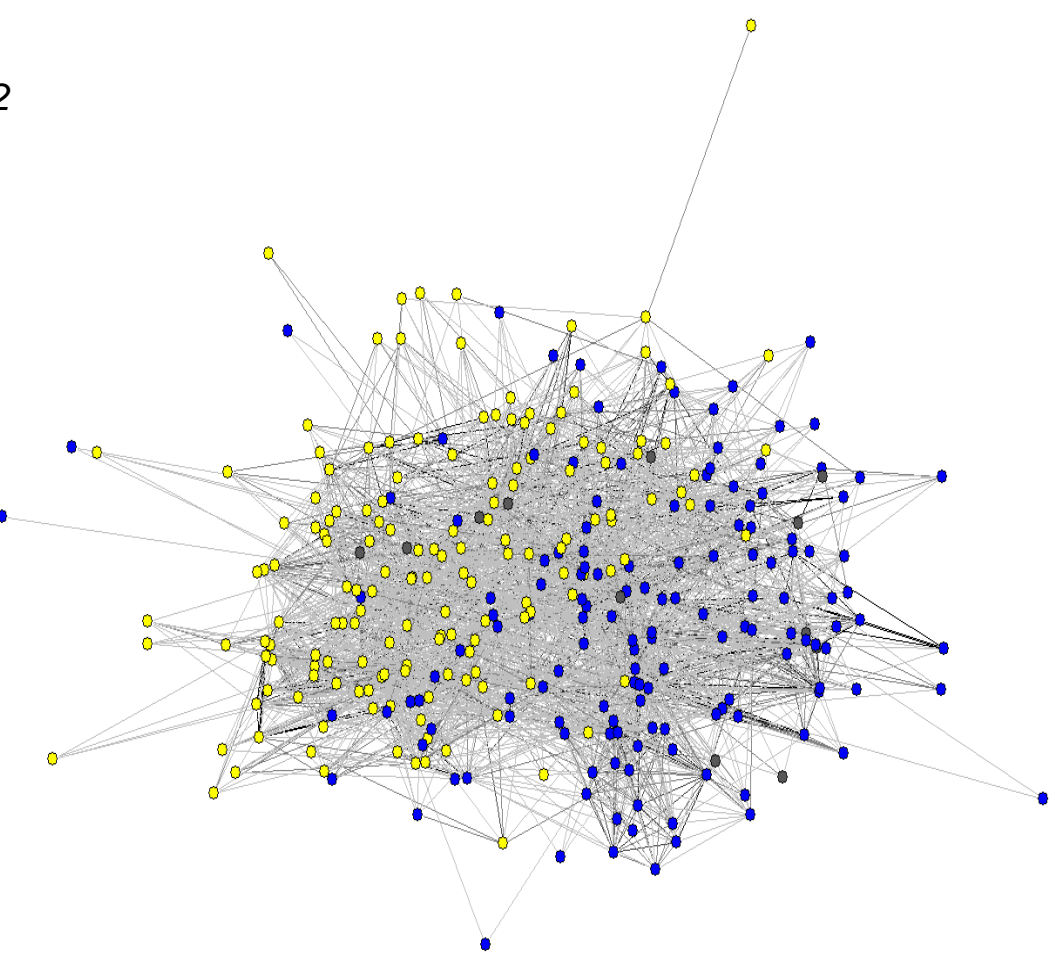

b) Ethnic6

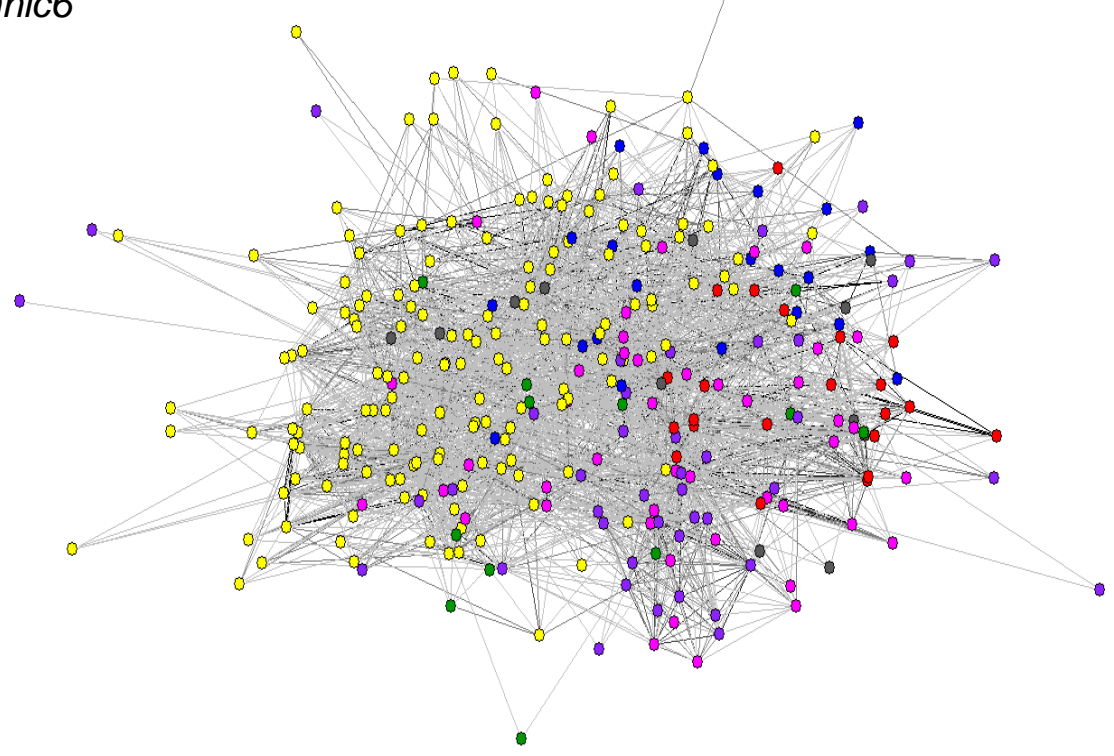

Figure 3. Visualisation of the network using the Fruchterman-Rheingold 2D algorithm in Pajek. a) nodes coloured by Ethnic2 (white=yellow; non-white=light blue) b) nodes coloured by Ethnic 6 (white=yellow; black=green; Indian=purple;

Pakistani/Bangladeshi=red; Chinese=dark blue; 'all other'=pink). Nodes with missing ethnic data coloured dark grey. 

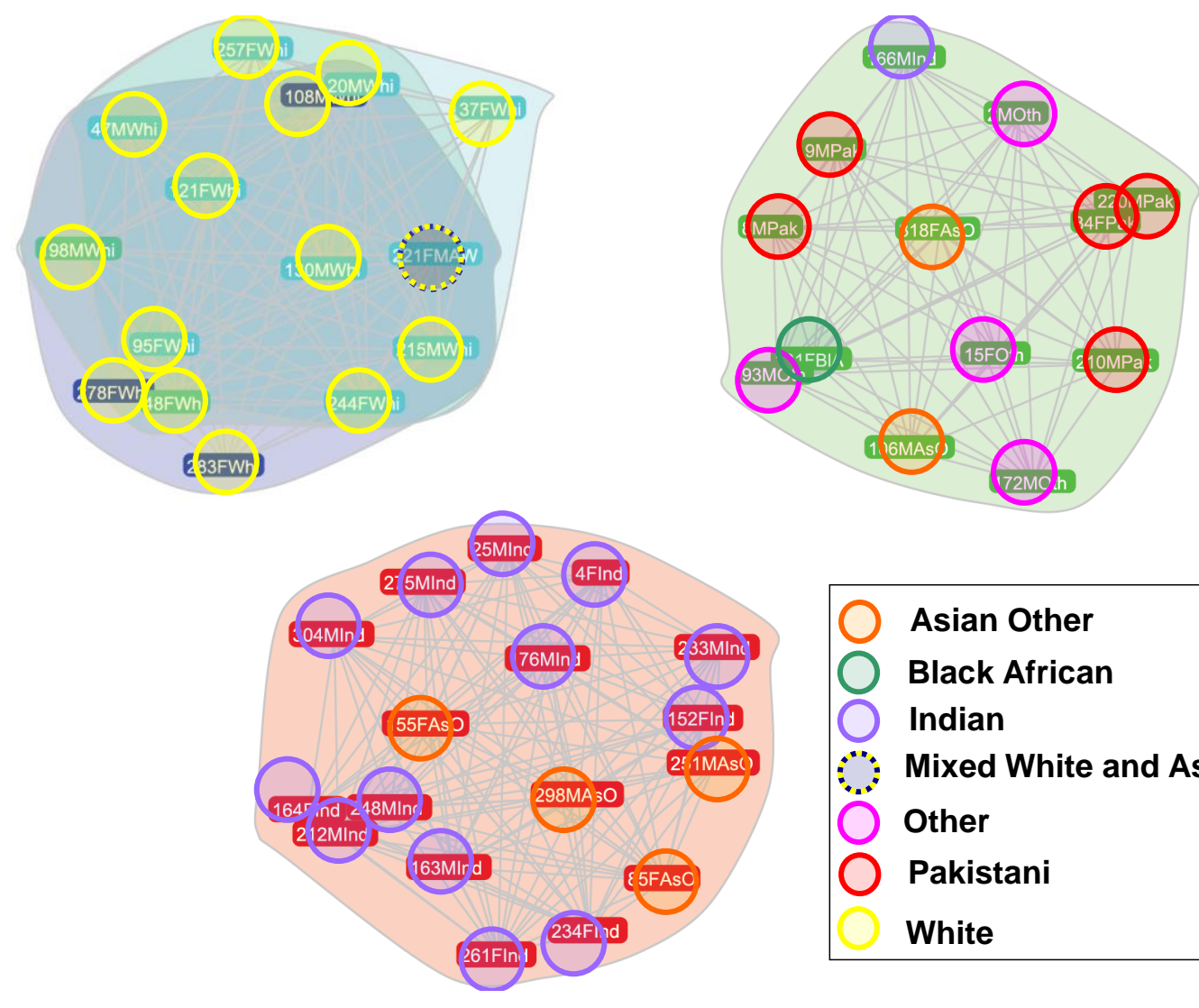

\begin{tabular}{|ll|}
\hline & Asian Other \\
& Black African \\
& Indian \\
\hdashline & Mixed White and Asian \\
\hdashline & Other \\
& Pakistani \\
& White \\
\hline
\end{tabular}

Figure 4: The five communities of 10-cliques identified in the network by C-finder software. There were two distinct all-non-white communities $(n=17$ and $n=13)$, and three communities (all $n=10$ ) containing white students and one mixed white and Asian student. The three white communities shared all but five students. They therefore overlap considerably and appear almost as one community in the diagram . Of the non-white communities, one was largely Indian with four 'Asian Other' nodes. The other contained five Pakistani, four 'Other', two 'Asian Other', one Indian and one black African node. The numbers on the nodes are the unique identifiers and the letters refer to sex (M or F) and ethnicity $(\mathrm{AsO}=\mathrm{Asian}$ Other; $\mathrm{BlA}=$ black African; Ind=Indian; Oth=Other; Pak $=$ Pakistani; Whi=white $)$. 
a) Social network by actual ethnic group

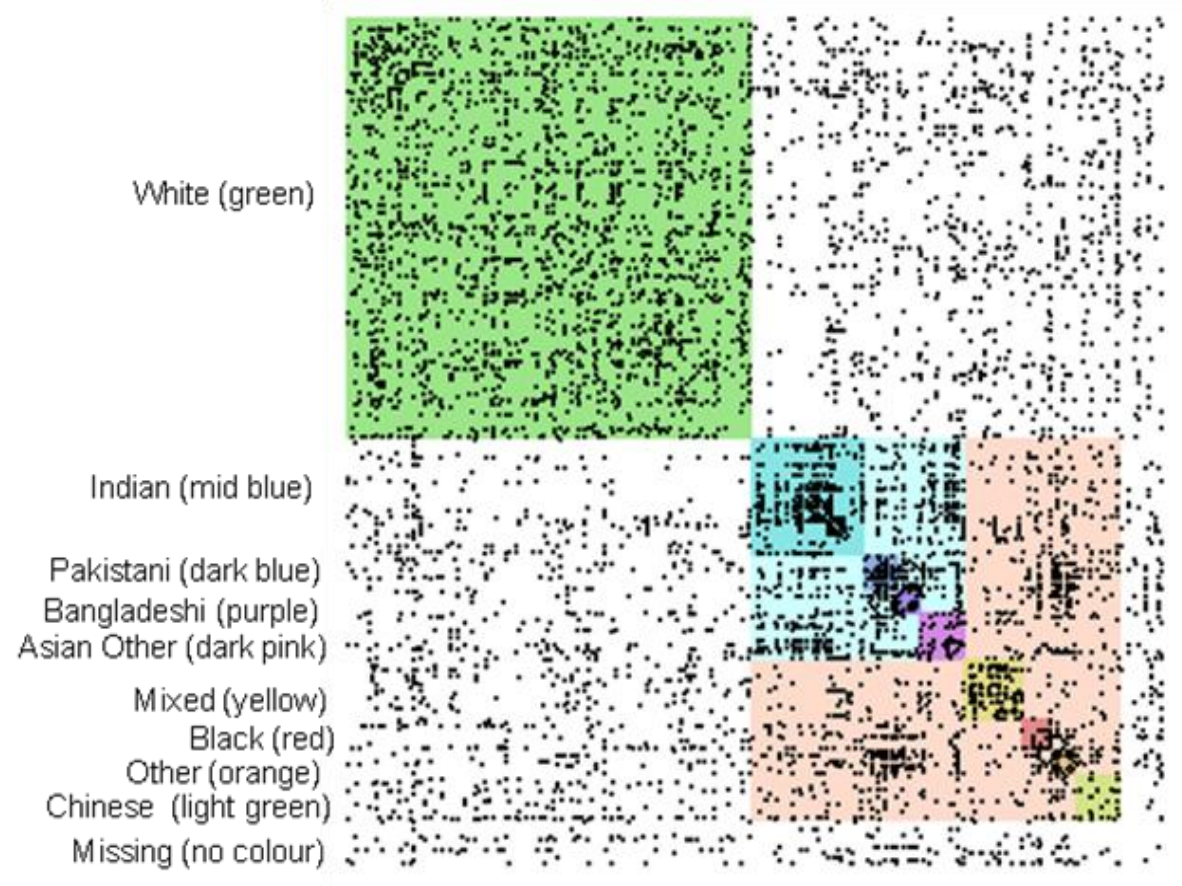

b) Social network with participants randomly allocated to ethnic groups

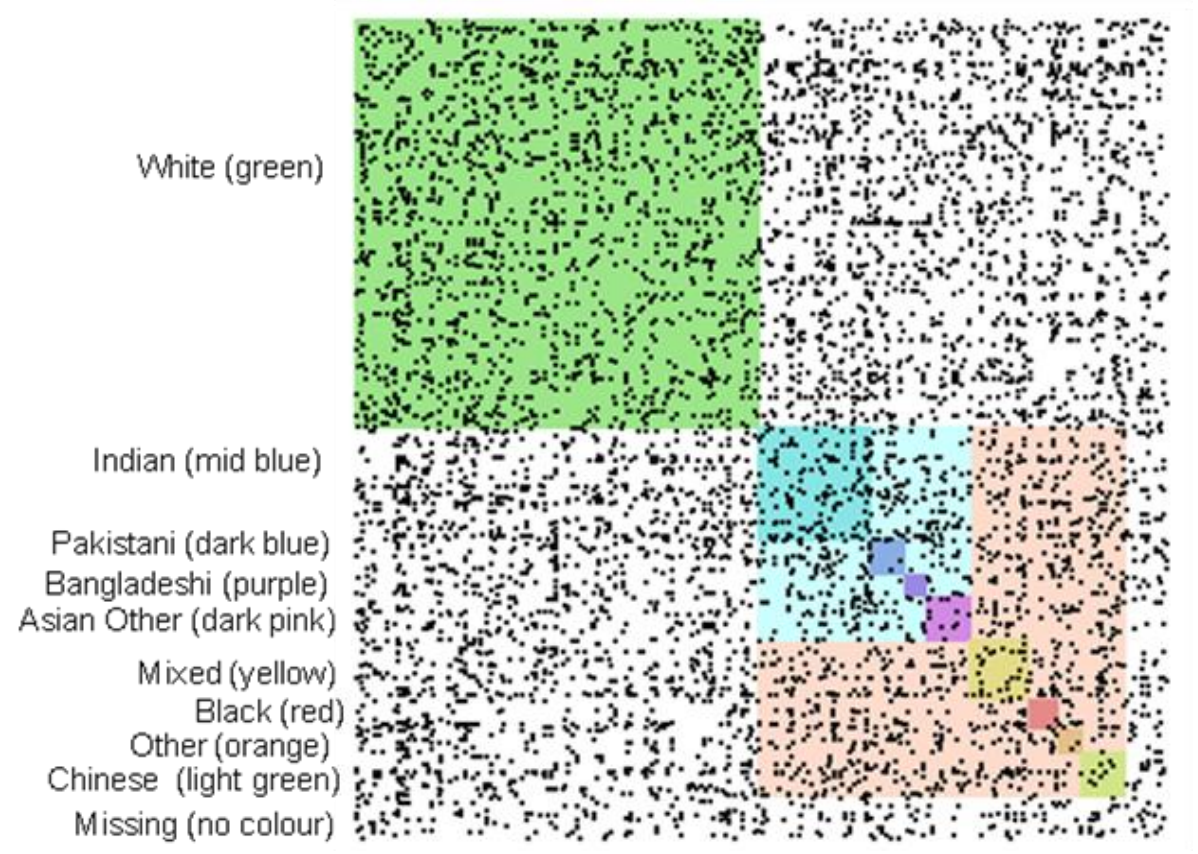

Figure 5. The social network and ethnicity. Both figures are symmetrical along the diagonal. Dots represent links (friendships) between pairs. Dots within coloured squares show friendships within ethnic groups; dots in the light blue area show friendships between the four Indian subcontinent groups; and dots in the light pink area show friendships between Indian Subcontinent groups and other non-white groups. All are more prevalent in the actual ethnicity figure a) than in the random ethnicity figure $b$ ). Dots in the upper right and lower left quadrants show friendships between white and nonwhite groups. They are more prevalent in figure b). 


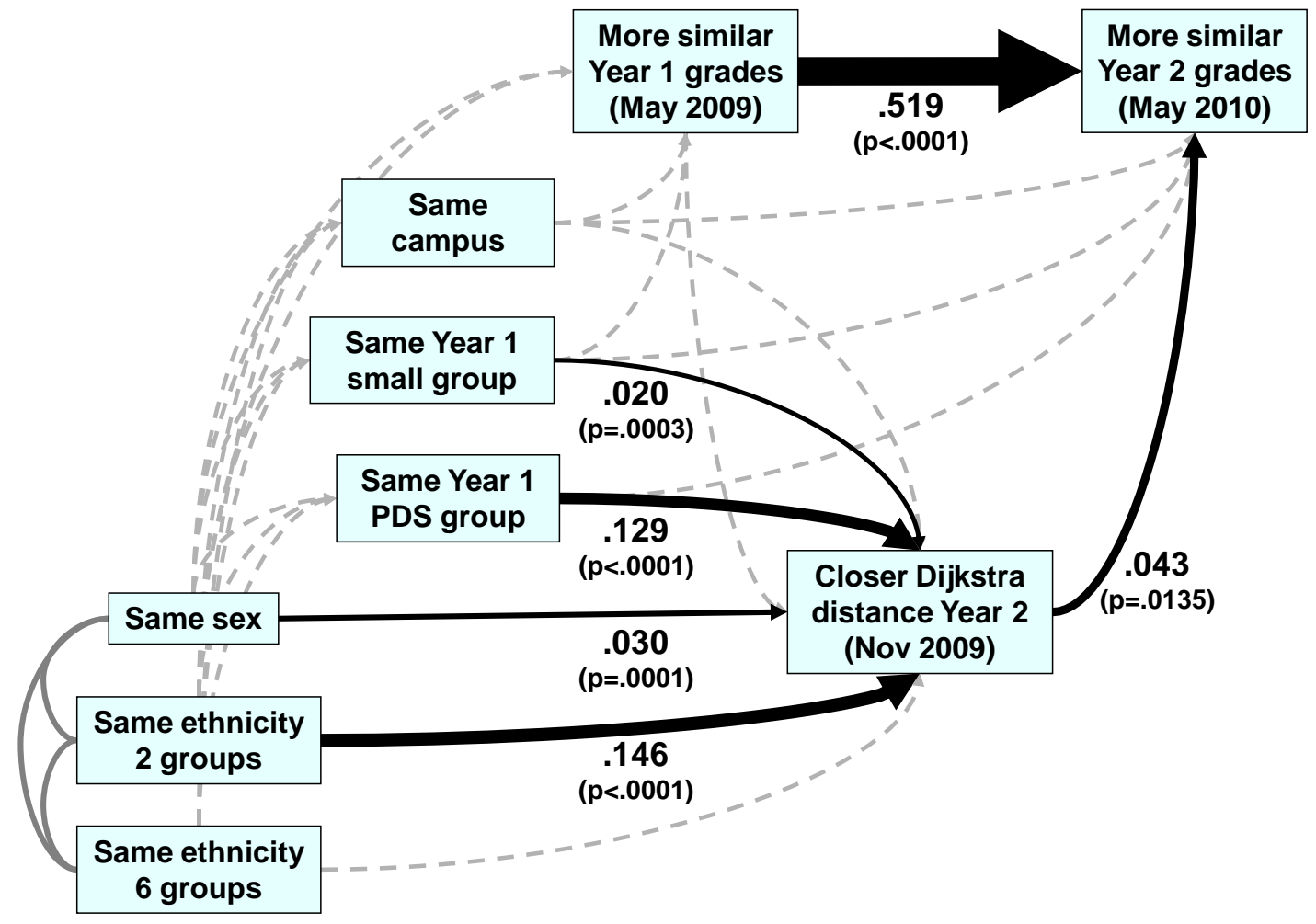

Figure 6. Path model showing the relationships between variables in the multiple regression analyses. Solid lines represent statistically significant relationships with their beta weights. Single headed arrows represent hypothesised causal paths. Double headed arrows represent simple correlations. Grey lines show tested but non-significant relationships. 